\title{
CULTURAS DA INFÂNCIA: OS MODOS COMO AS CRIANÇAS ASSISTEM E INTERAGEM COM AS SÉRIES DE ANIMAÇÃO
}

\author{
PATRÍCIA GONÇALVES NERY ${ }^{1}$ \\ ORCID: https://orcid.org/0000-0003-0273-297X \\ TERESA CRISTINA REGO ${ }^{2}$ \\ ORCID: https://orcid.org/0000-0002-1164-8094
}

\begin{abstract}
RESUMO: Na sociedade atual, inúmeros produtos e conteúdos midiáticos, apropriados e reelaborados criativamente pelas crianças em processos de interação com os pares e com os adultos, integram as chamadas culturas da infância. Dentre esses produtos culturais, as séries de animação veiculadas pela TV (aberta ou fechada) participam, com destaque, das experiências cotidianas das crianças. O objetivo deste artigo é apresentar a primeira parte dos resultados de uma investigação que buscou compreender os modos como as crianças assistem, interagem e significam as séries de animação. A pesquisa foi realizada no âmbito da investigação qualitativa e participativa, por meio de uma análise microssocial, de cunho interpretativo, integrada à área da Sociologia da Infância a qual se conjugou de forma interdisciplinar com os Estudos Culturais Latino-americanos da área da Comunicação. Realizada com um grupo de estudantes de nove e dez anos, a pesquisa examinou o ponto de vista das crianças a partir da utilização de estratégias metodológicas diversificadas que envolveram observação participante, entrevistas em pequenos grupos e oficinas de trabalho. Os resultados obtidos revelam, dentre outros aspectos, que as crianças não assimilam simplesmente ao que assistem como meras espectadoras passivas. Em multiconectividade com outras mídias, elas participam de um processo ativo, interativo e dialogal, sempre relacionado ao contexto sociocultural em que estão inseridas. Eles permitem apontar também a grande responsabilidade (nem sempre percebida ou reconhecida) envolvida na produção de conteúdos e produtos midiáticos para as crianças, de um modo geral, e, em particular, das séries de animação voltadas ao público infanto-juvenil.
\end{abstract}

Palavras-chave: Culturas da infância, multiconectividade, produtos midiáticos, séries de animação, televisão.

\section{CHILDHOOD CULTURES: THE WAYS CHILDREN WATCH AND INTERACT WITH THE ANIMATED SERIES}

\begin{abstract}
In today's society, numerous products and media content, appropriated and creatively reworked by children in processes of interaction with peers and adults, integrate the so-called childhood cultures. Among these cultural products, the animated series broadcast by TV participate, with emphasis, in the daily experiences of children. The objective of this article is to present the first part of the results of an investigation that sought to understand the ways children watch, interact and mean the animation

\footnotetext{
${ }^{1}$ Professora da Faculdade de Educação da Universidade do Estado de Minas Gerais (UEMG). Belo Horizonte, MG, Brasil. <patricianery145@gmail.com>

2 Professora Titular da Faculdade de Educação da Universidade de São Paulo (USP). São Paulo, SP, Brasil. <teresare@usp.br>
} 
series. The research was carried out in the scope of qualitative and participative research, by means of a microsocial analysis, of an interpretative nature, integrated to the area of Child Sociology, which was combined in an interdisciplinary way with the Latin American Cultural Studies in the area of Communication. Carried out with a group of nine and ten-year-old students, the research examined the point of view of children from the use of diversified methodological strategies involving participant observation, interviews in small groups and workshops. The results obtained reveal, among other aspects, that children do not simply assimilate what they see as mere passive spectators. In multiconnectivity with other media, they participate in an active, interactive and dialogical process, always related to the sociocultural context in which they are inserted. They also point out the great responsibility (not always perceived or recognized) involved in the production of content and media products for children in general, and in particular, the animation series aimed at children and young people.

Keywords: Childhood cultures, multiconnectivity, midiatic products, animation series, television.

\section{CULTURAS DE LA NIÑEZ: LAS FORMAS EN QUE LOS NIÑOS VEN E INTERACTÚAN CON LAS SERIES DE ANIMACIÓN}

RESUMEN: En la sociedad actual, numerosos productos y contenidos de los medios de comunicación, apropiados y reelaborados creativamente por los niños en procesos de interacción con sus pares y adultos, integran las llamadas culturas de la niñez/infancia. Entre estos productos culturales, las series de animación transmitidas por la televisión (abierta o cerrada) participan, con énfasis, en las experiencias cotidianas de los niños. El objetivo de este artículo es presentar la primera parte de los resultados de una investigación que buscó entender las formas en que los niños miran, interactúan y significan las series de animación. La investigación se realizó en el ámbito de la investigación cualitativa y participativa, mediante un análisis micro social, de carácter interpretativo, integrado al área de la Sociología del Niño, que se combinó de manera interdisciplinaria con los Estudios Culturales Latinoamericanos en el área de la Comunicación. Realizada con un grupo de estudiantes de nueve y diez años de edad, la investigación examinó el punto de vista de los niños a partir del uso de estrategias metodológicas diversificadas que incluían la observación de los participantes y entrevistas en pequeños grupos y talleres. Los resultados obtenidos revelan, entre otros aspectos, que los niños no asimilan simplemente lo que ven como simples espectadores pasivos. En la multiconectividad con otros medios, participan en un proceso activo, interactivo y dialógico, siempre relacionado con el contexto sociocultural en el que son puestos. También señalan la gran responsabilidad (no siempre percibida o reconocida) involucrada en la producción de contenidos y productos mediáticos para los niños en general y, en particular, las series de animación dirigidas a niños y jóvenes.

Palabras clave: Culturas de la niñez, multiconectividad, productos mediáticos series de animación, televisión.

\section{INTRODUÇÃO}

As crianças conjugam, em suas experiências diárias, nas brincadeiras e conversas infantis, informações e imagens que circulam nas mídias (BUCKINGHAM, 2007; GOMES, 2012), as quais encontram-se repletas de narrativas elaboradas por grandes corporações, signatárias das modernas indústrias de mídia. Ao buscar uma constante produção e adaptação de produtos para o mercado global, tais conglomerados fornecem às crianças uma cultura comum que transcende as fronteiras nacionais e as diferenças culturais locais (BUCKINGHAM, 2007).

Nesse sentido, Buckingham considera que (2010, p.42), “[...] a infância contemporânea está permeada e, em alguns sentidos, até definida pela mídia moderna". Ou seja, as crianças estão vivendo cada vez mais infâncias midiáticas, promovendo assim uma mudança no próprio significado de infância na sociedade contemporânea, a qual passa a ser definida, de certa forma, por meio das interações das crianças com as mídias eletrônicas. Estaríamos, pois, diante de uma infância digital? 
Dentre essas mídias, destacam-se, nas culturas da infância, as séries de animação, principal conteúdo audiovisual televisivo oferecido às crianças brasileiras. Conhecidas, por grande parte delas, como desenhos animados, trata-se de um produto cultural integrado a um universo televisivo que tem se tornando mais complexo para as crianças em virtude dos avanços da comunicação na direção da multiplicidade de canais e de inúmeras formas de distribuição de conteúdos. A televisão, nesse sentido, vem se dirigindo às crianças de modo cada vez mais especializado e segmentado. Segundo Carmona (2016), a segmentação da audiência, que se caracteriza pela divisão do universo infanto-juvenil por faixas etárias ou blocos, baliza a programação e a produção para crianças.

As séries de animação caracterizam-se por uma narratividade fragmentada e descontínua, resultado tanto da forma de exibição das séries na TV, cujos episódios são apresentados separadamente, como pela presença dos breaks comerciais, os quais separam cada parte do episódio. Para que sejam compreendidas, as narrativas das séries de animação apoiam-se, segundo Nesteriuk (2011), na intertextualidade e na memória do espectador.

Tais narrativas, especificamente as que são dirigidas às crianças, apresentam histórias ficcionais imaginárias, muitas vezes curtas, ágeis, de ação e diálogos rápidos, repletas de diferentes esquemas lúdico-dramáticos, nos termos de Fuenzalida (2008).

Ao interagir com as séries de animação veiculadas pela TV, as crianças o fazem por meio das ações do olhar, do escutar, do sentir, do imaginar e do dialogar, as quais integram o processo multimediado da recepção. Apesar do ato de ver TV ser uma ação individualizada, a produção de sentidos no processo de recepção é social e coletiva (GENEROZO, 2015). Tais sentidos produzidos não estão contidos nos conteúdos midiáticos, mas são resultado da elaboração dialógica entre os sujeitos e os conteúdos midiáticos, em contextos sócio-históricos concretos e compartilhados em espaços sociais. O processo de recepção é, pois, sempre interação, mediado de múltiplas maneiras e com alcance e circulação para muito além do momento de ver TV.

Nesse processo, as crianças interagem com essas narrativas de diferentes modos e recriam continuamente os conteúdos televisivos, tanto no intercâmbio com as instituições socializadoras como nos espaços de sociabilidades próprias. Os modos como as crianças interagem com os referentes televisivos e os sentidos que produzem no processo de recepção integram as culturas da infância.

Com o propósito de oferecer contribuições para o campo da Sociologia da Infância, o presente artigo tem como objetivo apresentar a primeira parte dos resultados da pesquisa "Culturas da infância: os modos como as crianças assistem, interagem e dão sentidos às narrativas das séries de animação" ${ }^{3}$. Ainda que existam pesquisas importantes relativas ao tema Mídia e Infância em áreas multidisciplinares (PACHECO, 1999; FERNANDES, 2003; SALGADO, 2005; GENEROZO, 2015), cujos trabalhos, ao considerar as crianças como receptoras ativas das mensagens televisivas, buscam compreender os sentidos que elas produzem acerca das séries de animação, nas práticas sociais difundidas e incorporadas na cotidianidade, é fundamental o adensamento de pesquisas, nesse campo, que investiguem como as crianças se constituem como sujeitos produtores de cultura (FERNANDES, 2003).

Nesse sentido, no quadro das culturas da infância, buscamos analisar as especificidades das formas e conteúdos que assumem as séries de animação veiculadas pela TV e os processos de produção de sentidos elaborados pelas crianças em suas experiências sociais e culturais. Para alcançar tal fim, foi necessário construir um diálogo com diferentes áreas do conhecimento com o objetivo de compreender algo integrado e complexo: os sentidos culturais elaborados pelas crianças, em seus contextos de existência, a partir de uma concepção de "[...] infância autora e reprodutora de sua cultura infantil" (ARROYO, 2015, p. 16). Para tanto, optamos por realizar uma pesquisa de análise microssocial, de cunho interpretativo, integrada à área da Sociologia da Infância, a qual se conjunga de forma interdisciplinar com os Estudos Culturais Latino-americanos de mídia e recepção.

Com base nos pressupostos apresentados, buscamos, na primeira parte da pesquisa, objeto de discussão do presente artigo, compreender como as crianças assistem e interagem com as séries de animação: o que mais assistem; onde e por quanto tempo assistem; com quem assistem; de que modos assistem; como realizam suas escolhas; que histórias, personagens, papéis e temas culturais são mais

\footnotetext{
${ }^{3}$ Pesquisa de doutoramento realizada no âmbito da Faculdade de Educação da Universidade de São Paulo e financiada parcialmente pela Fundação de Amparo à Pesquisa do Estado de Minas Gerais (FAPEMIG).
} 
valorizados por elas e como se identificam com as histórias. Tais resultados nos possibilitaram compreender como as crianças se relacionam com as narrativas das séries de animação veiculadas pela mídia televisiva em suas práticas cotidianas. Na segunda etapa da pesquisa, dedicamo-nos a investigar como e que sentidos as crianças constroem no processo de recepção das narrativas audiovisuais.

O presente texto está organizado em três seções. Na primeira, refletimos sobre alguns aspectos relativos à mídia e à infância, com o objetivo de dialogar com estudos anteriores e também de situar a infância e as crianças no contexto da dinâmica comunicacional e midiática atual. Na segunda, discorremos a respeito da metodologia adotada para a realização do estudo em tela. Na terceira seção, apresentamos os resultados da pesquisa relativos aos modos como as crianças assistem e interagem com as narrativas das séries de animação.

\section{A INFÂNCIA E AS CRIANÇAS NA DINÂMICA COMUNICACIONAL DA SOCIEDADE CONTEMPORÂNEA}

No processo de comunicação, de acordo com Faxina e Gomes (2016), conteúdos elaborados e compartilhados socialmente circulam num fluxo contínuo e produzem resultados práticos e simbólicos. Tais conteúdos são a expressão da vida em sociedade. Um dos elementos dessa dinâmica comunicacional são os processos midiáticos, formados a partir da relação mútua da mídia com os processos culturais ancorados nas relações sociais. A mídia, compreendida como meios eletrônicos que desempenham papel de enuncidadores da informação, apropria-se de conteúdos e os trabalha numa dinâmica complexa de significação com e para a sociedade, numa via de mão dupla (FAXINA; GOMES, 2016).

Com o advento das tecnologias digitais na sociedade contemporânea, esse processo humano de comunicação é potencializado pelos meios eletrônicos sofisticados. Para o antropólogo Sodré (2010 apudFAXINA; GOMES, 2016), apesar dessas novas mídias digitais, de forma geral, afetarem o cotidiano da vida pessoal e coletiva e criarem novos hábitos para a sociedade, tais modificações não significam uma revolução no campo da informação e, sim, uma transformação tecnológica. De acordo com o pesquisador, "[...] uma revolução modifica não só o hábito de uma sociedade, mas também transforma o próprio sentido da sociedade, mudando não apenas o comportamento social como também a teleologia do modo de produção" (SODRÉ, 2010, p.37 apud FAXINA; GOMES, 2016, p.182). As mudanças vividas pelas sociedades atuais, tendo a tecnologia como processo deflagrante, apesar de promoverem uma nova forma de sociabilidade, isto é, uma forma de vida intensamente tecnológica, com tempos e espaços próprios, não vêm acompanhadas, necessariamente, de alterações efetivas na forma econômica e na vida política das sociedades.

Essa nova sociabilidade de que nos fala Sodré tem, como tela de fundo, a realidade digital sendo definida como uma nova ambiência que se caracteriza por um novo modo de ser no mundo, segundo Faxina e Gomes (2016). Para esses autores, estamos em uma sociedade em midiatização, a qual gera uma nova forma de viver na sociedade. Nesse novo contexto, os meios não são utilizados como instrumentos, mas fazem parte da autocompreensão social e individual: “[...] a pessoa não é um 'eu' que utiliza instrumentos como extensão do seu corpo, mas um indivíduo que se autocompreende como um ser que preza as suas relações e conexões através da existência dos instrumentos tecnológicos da comunicação" (FAXINA; GOMES, 2016, p.187).

Nesse novo cenário, percebe-se a passagem da comunicação de massa, a qual se caracteriza pela centralidade, verticalidade e por ser unidirecional, à dimensão tecnológica do virtual na qual o usuário insere-se pela participação direta, substituindo a participação contemplativa, com a possibilidade de entrar e se mover nos ambientes digitais. Além disso, as novas tecnologias provocam uma convergência de mídias e formas de comunicação, até então separadas, fundidas numa forma de intertextualidade infinita (BUCKINGHAM, 2007). Trata-se de um universo no qual, a partir de um conteúdo audiovisual, criam-se inúmeros outros em diferentes suportes, sendo que cada um deles aporta a sua especialidade complementando, assim, a produção audiovisual (MASCI, 2016).

Segundo Gómez (2014), a possibilidade de uso de diferentes canais, linguagens e combinações entre essas mídias imprime um caráter mais integral à atividade comunicativa. Nessa direção, os produtores de mídia vêm adotando, cada vez mais, formas diferentes de contar uma história. Trata-se das narrativas transmidiáticas, cujas histórias vão se desenrolando através de múltiplos suportes 
midiáticos, ampliando e expandindo o universo das narrativas (FERNANDES, 2011). Os sofisticados aparatos, acompanhados de novos conceitos tecnológicos, vão assim promovendo no campo social uma intensa interatividade e conectividade.

De acordo com Gómez (2014, p.72), outro aspecto importante a considerar é a onipresença da condição mercantil. $\mathrm{Na}$ visão do autor, cada vez mais a definição e a ampliação dos conteúdos audiovisuais estão sob o controle do mercado. Sobram poucos espaços livres do mercantil: “[...] o mercado e suas exigências de consumo e de inovação é que estão definindo o rumo e o estado de comunicação e seus dispositivos". Impelidos pela competitividade, até os meios públicos e estatais se submetem às regras do mercado, porém em níveis e com funções diferenciadas.

Mesmo em um cenário fortemente mercantilizado e tecnologicamente sofisticado, a mídia não pode determinar uma visão sobre algo, embora atue como condição de agenda para a sociedade e, por isso, como reestruturadora de percepções, sensibilidades e cognições. Como instância de poder, a mídia, ao mesmo tempo em que afeta a sociedade, é, ela própria, afetada pelas instituições sociais, jurídicas, religiosas e de mercado (FAXINA; GOMES, 2016).

Diante dessa avalanche de novidades, de meios e dispositivos comunicacionais, o que se observa de fato, segundo Gómez (2014, p.140), é que o novo não destroi o velho; eles coexistem de alguma maneira. "Além disso, cada meio cria-se ou associa-se a ritualidades, hábitos e tradições que não são abandonadas facilmente". De acordo com o pesquisador, a tecnologia pode se transformar rapidamente, a cultura não. Mesmo participando de mediações tecnológicas com grande força e capacidade para inverter tendências com maior rapidez do que outras mudanças históricas, a alteração de costumes e preferências exige mais tempo.

A compreensão das relações das crianças com as mídias, numa sociedade considerada em midiatização, relaciona-se diretamente com a compreensão do estatuto social da infância e da criança. Contudo, as ideias, pensamentos, imagens e emoções relacionadas à concepção de infância não são dadas, tampouco fixas, como afirma Buckingham (2007, p.149), uma vez que "[...] estão sujeitas a um contínuo processo de definição - a uma luta social pelo significado". Como categoria social de tipo geracional, a infância participa de forma essencial da estrutura da sociedade e conjuga-se nas várias dinâmicas sociais relativas aos contextos geográficos, culturais, raciais, étnicos, etários, de gênero e de classes. Configurase, pois, a partir de continuidades, conflitos e transformações ocorridas ao longo da história (GOMES, 2012; DEBORTOLI, 2008). A infância, portanto, “[...] é produzida pelo conjunto da sociedade a partir de ideias, práticas e valores que se referem, sobretudo, às crianças, sendo que esses elementos são estabelecidos, difundidos e reproduzidos social e culturalmente" (GOMES; AVANZINI, 2015, p.9).

Nesse sentido, as relações das crianças com as mídias, segundo Buckingham (2007), só podem ser analisadas em contextos mais amplos de mudanças sociais e históricas, visto que mudanças nas mídias reforçam mudanças na infância e mudanças na infância reforçam mudanças nas mídias. Tratase de uma relação de influência mútua.

Portanto, segundo Buckingham (2010), é necessário ter cuidado ao se referir à infância contemporânea como geração digital, pois se trata, segundo o pesquisador, de uma forma de determinismo tecnológico, o qual estaria ancorado na ideia de que a tecnologia promove mudanças sociais ou psicológicas, independentemente de quem a usa ou de como é usada. Da mesma forma, tal concepção essencializa as crianças, obscurecendo tanto as diferenças como as desigualdades entre elas.

Outro aspecto importante a se considerar nas relações das crianças com as mídias é a sua participação ativa no processo de recepção dos produtos culturais midiáticos. Nessa perspectiva, como visto no início deste artigo, os grandes conglomerados midiáticos, fornecedores de uma cultura comum, operam por meio de um processo global de homogeneização que tende à negação das especificidades, das identidades e das culturas das crianças (SARMENTO, 2004; DOTRO; SALVIOLO, 2016). No entanto, ao acessar e interagir com os mesmos produtos culturais, as crianças não o fazem pondo de lado os processos simbólicos e culturais constituídos em seus grupos sociais; fazem-no pondo em ação características próprias inerentes a sua condição infantil. Tais modos de interação com os produtos culturais integram as culturas da infância, consideradas por Sarmento (2004) como o lugar próprio das crianças.

Para o autor, as crianças constituem, de forma sistematizada, modos próprios de ação e significação do mundo, distintivos dos modos adultos. Esses modos de ação, imaginação e significação 
resultam da convergência "[...] de fatores que se localizam, numa primeira instância, nas relações sociais globalmente consideradas e, numa segunda instância, nas relações inter e intrageracionais" (SARMENTO, 2004, p.373). As culturas da infância possuem, portanto, dimensões relacionais: constituem-se, em contextos concretos, nas interações entre crianças e seus pares e entre crianças e adultos, estruturando-se nessas relações formas e conteúdos representacionais próprios (SARMENTO, 2004; 2008)

Nesse sentido, as crianças, ao interagir com as instituições de veiculação e reprodução culturais traduzidas sob a forma de produtos e conteúdos culturais para a infância (SARMENTO, 2003; 2004; 2008), apropriam-se desses produtos e conteúdos, reproduzindo-os de forma interpretativa (CORSARO, 2011) por meio de suas linguagens multimodais - verbais, gestuais, iconográficas, plásticas -, da imaginação, do jogo simbólico, do brincar as quais constituem ações fundacionais das culturas da infância. Especialmente nas culturas de pares, consideradas por Corsaro (2011, p.39) como "[...] produções coletivas, inovadoras e criativas", elaboradas e partilhadas pelas crianças em suas interações com outras crianças, esses modos representacionais ganham sentido.

Por meio da ritualidade e da partilha no grupo geracional, as crianças estruturam o brincar, o jogo, as relações entre elas, pautando-as por negociações, lideranças e influências; exercitam suas capacidades de junção e de separação do real e da fantasia, assim como de transposição no espaço-tempo, rompendo com a linearidade temporal (SARMENTO, 2003; 2004; 2005). Nesse processo, de acordo com Sarmento (2005, p.373), o que ganha visibilidade é o fato de que as crianças são "[...] competentes e têm capacidade de formular interpretações da sociedade, dos outros, e de si próprias, da natureza, dos pensamentos e dos sentimentos, de o fazerem de modo distinto e de o usarem para lidar com tudo o que as rodeia”.

A partir dessa perspectiva, de acordo com Sarmento (2003; 2004), a compreensão das culturas da infância só pode ser elaborada na conjugação da análise da produção das formas culturais direcionadas à infância com a recepção dessas formas pelas crianças. Ademais, tal compreensão precisa levar em conta as formas culturais construídas de modo intra e intergeracional pelas crianças, as quais se caracterizam também como criadoras culturais.

\section{METODOLOGIA}

A pesquisa foi delineada no marco da investigação qualitativa e realizada a partir da perspectiva de valorização da participação infantil, a qual reconhece as crianças como sujeitos competentes e produtores de cultura, conforme preconizado por autores da Sociologia da Infância (ALDERSON, 2005; SOARES, 2006). De forma integrada a essa perspectiva, a investigação foi construída de forma articulada com os Estudos Culturais Latino-americanos da Comunicação.

Segundo Alderson (2005) e Soares (2006), a utilização de metodologias participativas exige da parte do pesquisador atenção e consciência para um conjunto de princípios éticos. Nesse sentido, a investigação com crianças deve ser pautada por uma relação de equilíbrio entre respeito, autonomia e proteção, na qual a ética de investigação é fundamentalmente informada pela concepção das crianças como um grupo social de direitos.

Construir uma relação ética de investigação com crianças, para além dos conceitos de alteridade e diversidade da infância, implica a consideração de princípios como a necessidade de as crianças compreenderem a proposta da pesquisa, seus objetivos, os instrumentos metodológicos para recolha das informações e os modos de construção e divulgação do conhecimento resultante da investigação.

Tais princípios abrangem também a indispensabilidade de a criança compreender que a sua participação é voluntária e que tem toda a liberdade para recusar participar em tal processo ou desistir a qualquer momento. Da mesma maneira, considera-se um princípio ético discutir com as crianças quais as técnicas de pesquisa que elas consideram mais adequadas ou com as quais se sentem mais confortáveis para participar. O consentimento voluntário e informado das crianças na investigação é um pressuposto ético fundamental ligado ao direito de participação (ALDERSON, 2005; SOARES, 2006).

Com base nesses princípios éticos, realizamos um estudo microssocial de cunho interpretativo em uma escola pública da região centro-sul de Belo Horizonte - Minas Gerais. O contato 
foi realizado diretamente com a direção da escola que, gentilmente, nos recebeu e, diante da solicitação de que gostaríamos de realizar uma pesquisa com crianças de 9 e 10 anos, nos indicou a turma do $4^{\circ}$ ano do Ensino Fundamental. Explicitamos o projeto às crianças e à professora da turma, detalhando os objetivos e as atividades que seriam realizadas no decurso da pesquisa. Em seguida, esclarecemos que, diante do que tinha sido apresentado a elas, a participação seria voluntária, mediante consentimento registrado. Das 32 crianças da turma, 27 aceitaram participar, sendo 17 meninos e 10 meninas, grupo esse constituído por crianças pardas e negras, em sua maioria (61,5\%), pertencentes aos estratos socioeconômicos baixos e médios, segundo dados da escola.

As estratégias metodológicas desenvolvidas envolveram a observação participante, a realização de entrevistas com as crianças e de oficinas de trabalho nas quais elas puderam escolher as séries de animação para assistir, debater e elaborar gêneros relativos ao que foi visto, tais como recontos, teleteatros, entrevistas e produção de animação. Nesses espaços, as trocas de impressões e as produções de conhecimentos pautaram-se nas linguagens, no diálogo e na imaginação das crianças.

Tais estratégias, desenvolvidas em 62 encontros, de três a quatro horas de duração cada, ao longo de seis meses, envolveram as crianças em diferentes níveis de participação. As diversas atividades foram elaboradas com o intuito de provocar e rentabilizar a participação das crianças a partir de seus próprios interesses e habilidades, levando em conta o momento de desenvolvimento no qual elas se encontravam.

Os resultados da primeira parte da pesquisa, relativos aos modos como as crianças assistem e interagem com as séries de animação, foco principal deste artigo, foram construídos a partir das informações recolhidas durante as entrevistas com as crianças. Tal estratégia metodológica foi realizada em três etapas: a primeira envolveu o planejamento e a organização dos grupos de crianças, com a ajuda direta da professora, cujos critérios considerados foram: a participação das crianças em pequenos grupos, com o objetivo de criar oportunidades para que todas pudessem falar e ser ouvidas pelos colegas, sem se cansarem pela extensão do tempo; a garantia da presença de meninos e meninas em cada grupo; a saída da sala de aula em horários que causassem menor impacto no fluxo do trabalho escolar e a finalização das entrevistas até o início de julho, para que tal atividade não fosse interrompida pelo período do recesso escolar.

A segunda etapa envolveu a realização das entrevistas. O roteiro foi construído a partir do enfoque global da audiência, com o objetivo de identificar as diferentes dimensões ativas e fontes de mediação que intervêm no processo de produção de sentidos dos referentes televisivos. Especificamente, buscou-se apreender, nas experiências cotidianas das crianças, que fatores atravessam, interferem e ajudam a configurar o processo de recepção; como as diferentes comunidades de apropriação e interpretação, a família e a escola, participam desse processo; como as matrizes culturais desse grupo de crianças ajudam nos processos de interação midiática; quais são as rotinas das crianças com relação à TV, suas escolhas e motivações relativas às séries de animação.

A entrevista foi organizada em quatro blocos temáticos, a saber, a criança no seu cotidiano; a criança e a TV; a criança e a programação da TV; a criança e os desenhos animados. Tal organização permitiu que conversássemos, de forma mais espontânea, dentro da proposta de cada tema.

$\mathrm{Na}$ terceira etapa, realizamos a devolutiva às crianças, momento esse bastante significativo para o grupo da pesquisa. $\mathrm{O}$ acesso das crianças às informações oferecidas por elas próprias, as quais contemplam um pouco de suas culturas, contribui para afirmar o quanto suas escolhas, suas opiniões e suas ações têm valor e importância. Ao mesmo tempo em que fortalece o grupo em torno de um conhecimento comum sobre o seu próprio universo, tal iniciativa permite que cada participante se considere importante, porque todos são contemplados em suas respostas, isto é, todas as respostas têm valor.

\section{OS MODOS COMO AS CRIANÇAS ASSISTEM E INTERAGEM COM AS SÉRIES DE ANIMAÇÃO DA TV}

As principais análises, construídas na primeira parte da pesquisa, relativas aos modos como as crianças assistem e interagem com as séries de animação da TV, são apresentadas a seguir em três subtópicos. O primeiro aborda as práticas e ações das crianças tecidas em diferentes espaços/tempos da 
vida cotidiana e o entrecruzamento de lógicas que presidem as relações reguladas pela escola e pela família, as quais influenciam as crianças na construção de suas experiências com as diferentes mídias, particularmente a televisiva. Em seguida, abordaremos a importância e o lugar que a televisão ocupa nos hábitos familiares, os significados que a TV ganha através dos usos, assim como os modos como as crianças assistem à televisão. O último tópico é dedicado às séries de animação na TV: as escolhas e as motivações das crianças da pesquisa no novo universo televisivo, amplo e segmentado, as séries de animação que mais assistem, seus temas e características comuns.

\section{O cotidiano multimediado e multitela das crianças}

No cotidiano das crianças da pesquisa, a escola mostrou-se ser uma importante referência na organização social da vida diária. É nesse espaço que elas se encontram e vivenciam múltiplas situações, integram-se e relacionam-se nos inúmeros microespaços, significando e ressignificando práticas que contribuem para as suas aprendizagens e sociabilidades. Para além do espaço escolar, a vida cotidiana das crianças se tece quase sempre nos limites domésticos de suas casas. Segundo Canclini (2013), a violência e a insegurança pública levam, tanto os grupos populares como os setores médios, a procurar na intimidade doméstica, em encontros confiáveis, formas seletivas de sociabilidade.

Portanto, é a partir do eixo escola que as crianças da pesquisa desenvolvem diferentes atividades no dia a dia, uma vez que, ao falarem a respeito de sua rotinas, discorrem num primeiro plano sobre as atividades em torno do ir e vir da escola, mostrando-nos, por meio do discurso, a centralidade que a escola ocupa em suas vidas.

As crianças, juntamente com as famílias, organizam seus tempos ao redor do que uma delas denominou "tempo útil e tempo livre". O tempo útil, nos disse Oliver, uma das crianças da pesquisa, "são os dias em que tem aula", e o tempo livre, os de fins de semana. Durante a semana, as crianças se dedicam às tarefas escolares. Não deixam de brincar, assistir aos programas na TV, aos YouTubers e nem de participar como jogadoras em diferentes dispositivos eletrônicos, mas fazem isso em tempos mais reduzidos. Nos fins de semana, raramente estudam. Apenas uma criança relatou estudar aos sábados. Brincam, passeiam, interagem com mídias eletrônicas e assistem mais aos programas de televisão.

A maior parte das crianças do grupo pesquisado assiste uma média diária de televisão entre duas e três horas e meia. No entanto, os tempos da assistência televisiva relacionam-se aos tempos da escola. Durante a semana, assistem mais TV após as aulas. Na parte da manhã, 80,8\% delas dizem assistir à televisão, sendo que 90,5\% assistem muito pouco tempo, "raramente passa de meia hora", segundo elas próprias, e 9,5\% dizem assistir à televisão entre duas e três horas.

À noite, todas as crianças dizem assistir à televisão, no entanto, a relação é invertida, isto é, $88,5 \%$ delas dizem assistir entre duas e três horas e 11,5\% assistem durante muito pouco tempo, visto que não conseguiram definir os horários e nem identificar os programas que assistem, pois não é algo frequente em suas rotinas.

Nos fins de semana, o acesso e a interação com as mídias se intensificam, principalmente com relação aos programas de TV, aos videogames e aos canais de YouTube. No grupo pesquisado, 88,5\% dizem assistir TV entre três e quatro horas por dia nos fins de semana, enquanto 11,5\% dizem assistir até dez horas de televisão em um único dia.

Dentre as múltiplas telas com as quais as crianças interagem diariamente, a televisão mantém onipresença em seus lares. Entretanto, ao lado do aparelho de TV, outra tela vem atraindo maciçamente a atenção das crianças: o celular. No grupo pesquisado, 84,6\% dizem ter celular; desses, $55,0 \%$ dizem ter celular próprio, $41,2 \%$ dizem fazer uso compartilhado com a mãe e 3,8\% dizem compartilhar com os primos.

Para as crianças da pesquisa, o celular é um importante instrumento de interatividade e comunicabilidade nos grupos de pares. Entre as crianças, $46 \%$ dizem utilizar os telefones celulares para interagir em rede de comunicação pelo Whats $A p p$, fazem isso mais restritamente com os amigos e colegas de sala de aula. Essa prática é comum entre as crianças que têm celulares próprios. As crianças que compartilham celulares com as mães dizem não acessar o Whats $A p p$ e nem redes sociais, utilizando os celulares mais para participar de videogames.

Além de assistir à televisão, prática comum a todas as crianças, as atividades midiáticas mais praticadas por elas em suas rotinas são participar de videogames, assistir aos YouTubers e aos vídeos que 
ensinam a jogar pelos canais de YouTube. No grupo, 96\% das famílias, segundo as crianças da pesquisa, têm em casa pelo menos um dispositivo ligado em rede o que amplia enormemente a participação delas em atividades virtuais.

Consoles de videogames, como Xbox, PlayStation ou Wii, foram citados por poucas crianças. A grande maioria acessa redes sociais ou de comunicação, joga e assiste aos canais de YoutTubers em equipamentos mais portáteis e individualizados como celulares e tablets os quais permitem experiências mais personalizadas e intensas. Diferente, por exemplo, de assistir aos programas pela TV de forma compartilhada, cujo modo de assistir sempre depende de negociações intragrupo.

As famílias do grupo pesquisado, além de consumirem aparelhos tecnológicos midiáticos diversificados, investem na TV por assinatura, adquirindo pacotes que incluem diversos canais infantis (85\%) e na assinatura da Netflix (31\%), uma provedora global de filmes e séries de televisão, via streaming, no qual os conteúdos ficam disponíveis para ser acessados pelo usuário.

Foi possível perceber que as famílias das crianças da pesquisa consideram importante oferecer meios de entretenimento e conectividade aos filhos, pois adquirem diferentes aparatos tecnológicos como consoles de jogos eletrônicos e tablets para as crianças ou compartilham com elas aparelhos portáteis e de uso pessoal como o celular. As crianças demonstram isso em seus relatos, como nos narra Tuzinho ${ }^{4}$, cujo compartilhamento tecnológico é realizado com os primos:

Pesquisadora: [...] e o videogame, Tuzinho?

Tuzinho: Eu tinha videogame, não é esse Xbox, Playstation não, era bem antigo.

Pesquisadora: Você ainda joga nele?

Tuzinho: Não, estragou....

Pesquisadora: E você joga onde?

Tuzinho: Eu gosto mais de jogar novos jogos.... Naruto, eu jogo atualmente é no celular e no computador, no celular eu gosto de... bem de noitinha, é hora de jogar, a gente pega o celular e começa a jogar junto.

Pesquisadora: De quem é o celular?

Tuzinho: É nosso, como eu sou o que tem menos tecnologia, tipo os meus primos têm console, têm celular, têm computador... é nosso... é dos primos.

A escola configura-se como eixo ao redor do qual as famílias organizam os tempos das rotinas com as crianças. Trata-se de uma organização temporal mais racional, com base na produção escolar, visto que as crianças "[...] ocupam espaço na divisão do trabalho, principalmente em termos de trabalho escolar, o qual não pode ser separado do trabalho na sociedade em geral [...]" (QVORTRUP, 2011, p.205).

É com base na lógica da racionalidade produtiva do trabalho escolar que as crianças e suas famílias definem o tempo dos estudos como o tempo útil, tempo programado e regulado pelas tarefas escolares, e o tempo dos fins de semana, menos controlado e mais dirigido às experiências hedônicas, no qual raramente estudam. Trata-se, portanto, de uma organização social de tempo mais homogênea e linear.

Essa mesma rotina, na qual os tempos são organizados a partir do trabalho escolar, ganha outros ritmos temporais engendrados pelo contato intensivo e interativo das crianças com diferentes telas - TV, celular, tablet - que as convidam a participar de experiências cada vez mais fluidas por meio de aparatos tecnológicos muitas vezes conectados em rede.

Tais experiências se realizam em outras configurações temporais que se diferenciam da homogeneidade do tempo social organizado a partir das tarefas escolares. Trata-se de uma temporalidade marcada pela simultaneidade das atividades, intensificada cada vez mais pelos modos como as crianças interagem com as mídias. Segundo Pillar (2013, p.306), a simultaneidade faz parte dos modos de ver e dizer sobre esta época: "Interagimos com diversas mídias e tecnologias concomitantemente, tornandose impensável realizar uma ação após a outra de forma sequencial".

No cotidiano das crianças da pesquisa, os tempos de assistência televisiva convergem com os tempos de brincar, jogar videogame assim como conversar por Whats App e, entre algumas, até realizar

\footnotetext{
${ }^{4}$ Os nomes das crianças aqui registrados são fictícios e foram sugeridos por elas mesmas antes do início da investigação proposta.
} 
tarefas escolares. Essas múltiplas interações, isto é, essa multiconectividade, nos termos de Gómez (2014), vivenciada pelas crianças rompe, em certa medida, com a ordem temporal sequencial e linear das ações também vivenciadas por elas no dia a dia.

A multiconectividade implica atenção partilhada. Isso significa que, ao realizar atividades de modo simultâneo, a atenção é dirigida em maior grau para uma atividade em detrimento de outra, que, no entanto, não desaparece da cena, fica disponível para ser reiniciada ou continuada a qualquer momento pelas crianças. É o que nos revela Roberta, Bob e Tuzinho em seus relatos:

Roberta: [...] quando estou na minha casa, assisto TV sozinha. Tem vez que eu assisto deitada, sentada, em pé, pulando no sofá, também tem vez que eu fico no eletrônico, no celular, brincando de outra coisa ou fazendo para casa, tudo ao mesmo tempo.

Bob: Eu assisto TV mais na sala, eu assisto com a minha mãe e eu assisto mexendo no celular. Às vezes, eu brinco também assistindo TV.

Tuzinho: Eu gosto de assistir TV mais deitado e comendo alguma coisa. Eu leio revistinha quando dá comercial, eu leio umas dez páginas.

Pelos relatos das crianças, foi possível perceber que grande parte das famílias não se preocupa com as experiências de multiconectividade vivenciadas por elas. Algumas, no entanto, se opõem ao movimento de convergência engendrado pelas mídias e orientam as ações das crianças em direção a experiências cotidianas marcadas por ações mais lineares e sequenciais:

Oliver: Minha mãe me diz que se a gente está brincando, não pode ficar brincando com a televisão ligada, porque a gente faz uma coisa primeiro e depois outra.

Segundo Gómez (2014, p.70), “[...] coexistência e não superposição do novo sobre o velho talvez seja o fenômeno central mais distintivo do que experimentamos atualmente em nossa condição de comunicantes".

A partir dos dados apresentados, foi possível perceber que o aumento expressivo do acesso e da interatividade das crianças da pesquisa com aparatos tecnológicos midiáticos não apresentou impacto no quantitativo de horas da assistência televisiva. Ou seja, o uso de novas tecnologias não apresentou um efeito substitutivo com relação à TV. O que tais experiências modificam é o modo como as crianças assistem à televisão, o qual se caracteriza pela simultaneidade e pela multiconectividade com outras mídias.

Por fim, é importante considerar que as crianças da pesquisa vivenciam suas experiências em espaços/tempos organizados por lógicas aparentemente opostas, porém entrecruzadas. Ou seja, circulam, interagem, produzem e trabalham em espaços/tempos mais rígidos, com tempos lineares e mais homogêneos, como a escola, e também vivenciam experiências em espaços/tempos mais fluidos, líquidos, integrados e intercambiados por brincadeiras, jogos, conversas com colegas por WhatsApp, programas em plataformas on demand, tutoriais de jogos, produção de canais de YouTube e perfis em páginas de Facebook. Esses espaços/tempos são permeados por linguagens articuladas e narrativas transmidiáticas, cujo universo fictício expande-se através de múltiplas plataformas, permitindo às crianças diversas experiências linguísticas, cognitivas, lúdicas e sensórias (ABREU, 2004; GÓMEZ, 2014).

Sendo essas experiências comuns às crianças da pesquisa, percebemos que elas circulam em espaços/tempos organizados por diferentes lógicas adequando e readequando suas ações. Tais atitudes indicam que agem com plasticidade e mobilidade nos entre espaços/tempos múltiplos que constituem suas cotidianidades, configuradas nas interrelações com a família, a escola e as mídias.

\section{Usos e modos de interação das crianças com a mídia televisiva}

As novas telas, como as de celular e as de tablet, ampliaram-se territorialmente, inclusive entre os setores sociais mais populares, a exemplo do grupo pesquisado. A mobilidade e a portabilidade que essas telas promovem vêm acompanhadas de intenso fluxo de conteúdos que perpassam diferentes mídias e que se reinventam a partir de cada uma delas ampliando, desse modo, a fluidez e a possibilidade de caminhos em múltiplas direções (LOPES, 2014). Nesse cenário transmídia, a TV também vem se transformando como meio maior de distribuição de conteúdo, seja por canais via cabo ou satélite ou por plataformas de serviços de mídia digital. 
Em todos os lares das crianças da pesquisa, há pelo menos um aparelho de TV, sendo que $64,5 \%$ delas dizem ter mais de um aparelho em casa. A televisão ocupa a centralidade nos lares das crianças, uma vez que todas afirmam ter pelo menos uma televisão presente na sala e 41,2\% afirmam ter um aparelho de TV em cada cômodo, exceto o banheiro. Para além da sala, 23,5\% das crianças, afirmam ter uma televisão também em seu próprio quarto.

A TV, ao integrar a cena familiar das crianças, ganha, nessa ambiência, sentidos outros que extrapolam a experiência sensória propriamente midiática ou de consumo, indo além da função informativa e de entretenimento. Nessa direção, a televisão, inserida de forma permanente no espaço social da casa e na cultura familiar, tem suas funções recriadas a partir dos diferentes usos que se fazem dela na cotidianidade.

Entre as funções recriadas para a TV no cotidiano das crianças participantes da pesquisa, a primeira diz respeito à possibilidade de congregar pessoas da família em um único ambiente da casa com a intenção de assistir a um gênero televisivo: trata-se da audiência em família. Para as crianças, assistir às telenovelas do gênero infantil, no horário noturno, é uma prática que reúne, particularmente, mãe, filhas e filhos, de diferentes idades. Trata-se, pois, de uma atividade sociocultural, "[...] compartilhada com seres queridos com que se vai construindo referentes comuns importantes em suas relações socioafetivas" (GÓMEZ, 2014, p.128).

Segundo Generozo (2015), a família constitui-se em uma mediação institucional, uma “comunidade de apropriação". É, pois, no ambiente doméstico que se dão as primeiras negociações entre o telespectador, a TV e os membros da família. Nessa esfera de significação, legitimam-se ou não os significados institucionalizados pela televisão. "E esta legitimidade está associada aos valores e atitudes que mantêm o receptor coeso às instituições sociais" (GENEROZO, 2015, p.91).

Outra função atribuída à TV, considerada por algumas crianças como fundamental e indispensável, diz respeito a sua capacidade de oferecer estabilidade emocional às pessoas da família em diferentes situações cotidianas, como nos apontam Tanque B e Tuzinho em seus relatos:

Pesquisadora: Completem a frase para mim: "E se na minha casa não tivesse televisão...".

Tanque B: Se na minha casa não tivesse TV, eu morria porque distrai muito a gente, faz meu irmão não brigar comigo, isso é ótimo....

Tuzinho: Se na minha casa não tivesse TV, meu irmão ia estragar um monte de coisa, meu irmão ia ficar balançando uma grade para poder ir para a televisão, para poder se distrair. Ele tem um ano. Se não tivesse TV, ele cairia da escada.

Para além dessas funções, percebemos, nos relatos de muitas crianças, que a televisão é vista como um meio capaz de dar vida ao ambiente, isto é, de criar uma sensação de movimento e de presença de alguém com quem se possa interagir, mesmo que virtualmente. Entre as crianças da pesquisa, 61,5\% dizem que a televisão precisa ficar ligada enquanto brincam. Para elas, a televisão cumpre um papel fundamental: "enche de presença" o espaço da brincadeira, que requer barulho, como o pátio do recreio da escola, parques ou praças que reúnem crianças em torno de brincadeiras, as quais nunca ocorrem em silêncio:

\footnotetext{
Augusto: Quando a televisão está desligada, eu peço para ligar de novo... porque eu não gosto quando eu fico brincando que só eu falando, eu gosto de outra pessoa falando.

Tuzinho: [...] eu vou lá pro último andar da casa para brincar porque eu não gosto de brincar assim sozinho. Para a brincadeira, a televisão tem que ficar ligada.

Camile: [...] como eu brinco sozinha, fica chato; eu prefiro deixar a televisão ligada para ficar barulho.

Lulu: A gente deixa a televisão ligada prá gente poder enxergar, enche a casa com barulho, com luz....

Gabriel: [...] entra mais "vapor” na casa, fica mais barulho, aí fica mais iluminado, né.
}

A presença extensiva e ubíqua da TV nos espaços da casa, visto que mais da metade das crianças diz ter um aparelho também nos quartos e em outros cômodos, não significa, necessariamente, que ela seja usada de forma expansiva e concentrada. Diferente disso, as crianças interagem de diferentes modos com a televisão. 
Em seus relatos, as crianças demonstram que, ao assistir televisão, ora o fazem com bastante atenção e interesse, ora se dispersam entre outras atividades. Esses modos de interação estão relacionados a diferentes fatores como o horário em que assistem à televisão, a disponibilidade para se dedicar a essa atividade na rotina diária, o programa televisivo, isto é, se se trata de série de animação, novela, filme ou série e com quem assistem:

Pesquisadora: E como você assiste TV?

Michelangelo: Eu assisto na sala com a minha irmã, deitado, sentado, comendo... às vezes, com o celular na mão jogando.

JP Power: Tem vez que eu assisto com meu pai, com a minha mãe, tem vez que eu brinco assistindo a TV, tem vez que eu assisto nem piscando os olhos de tanto que eu quero ver o filme. Tanque B: Eu assisto TV geralmente sozinho... jogado, do jeito que eu caio eu fico... eu brinco, brigo com meu irmão, como e fico dando pirueta.

Dragão do Gelo: Quando não tá passando nada legal, tipo quando acaba o desenho e começa lá, eu paro de brincar, fico vendo... de vez em quando, tá passando alguma coisa, eu pego o meu spinner e fico girando.

Camile: Eu assisto televisão sem piscar os olhos....

Fuenzalida (2002, p.52 apud DUARTE, 2008, p.14) aborda esses modos de interação em seus estudos e afirma que "[...] de maneira geral, a audiência outorga aos televisores ligados em casa uma atenção variável, uma atenção que pode ser concentrada em alguns programas, pode ser mais auditiva que visual em outros e completamente distraída em alguns casos". No mesmo sentido, Buckingham (2007, p.135) considera que as "[...] pesquisas sugerem que grande parte do uso das mídias está longe de ser comprometido ou engajado: ao contrário, na maioria das vezes esse uso é casual e distraído".

Outro ponto que merece ser analisado diz respeito à prática de brincar diante da tela de TV, experiência comum para algumas crianças que encontram, nas narrativas dos diversos gêneros, a matéria lúdica, tessitura da imaginação, para brincar e jogar:

JP Power: Eu olho se tá passando alguma coisa; se não tiver nada, eu pego um brinquedo e brinco, deixo a televisão ligada para depois falar alguma coisa. De vez em quando, fala alguma coisa que dá uma ideia para inventar uma história assim... uma brincadeira.

Mago dos Dragões: Eu não gosto de brincar no silêncio; eu gosto de brincar com uma música de fundo legal. Então, quando eu quiser brincar, ela serve de música de fundo.

Tanque B: A TV fica ligada para tudo... é costume, porque a gente fica brincando. Às vezes, eu vejo alguma coisa na TV que é legal, muito legal para brincar.

Brincar é um modo de interagir com os referentes televisivos. Segundo Fernandes (2003), a TV faz parte da brincadeira e, às vezes, é a brincadeira principal das crianças. Nesse sentido, Sarmento (2008, p.5) considera: "Com efeito, a natureza interativa do brincar das crianças constitui-se como um dos primeiros elementos fundacionais das culturas da infância. O brincar é a condição da aprendizagem, e, desde logo, a aprendizagem da sociabilidade."

Com relação ao brincar, $92,2 \%$ das crianças da pesquisa afirmam que as brincadeiras fazem parte de suas rotinas. Desse grupo, 73\% dizem brincar inspiradas em personagens, temas ou conteúdos dos seus programas preferidos de TV. Segundo Brougère (2010), para gerar brincadeiras a partir de repertórios televisivos, não basta que as imagens sejam apresentadas na televisão e nem mesmo que elas agradem. É preciso que elas possam ser integradas ao universo lúdico da criança, às estruturas que constituem a base dessa cultura lúdica e sobre as quais representações variadas são inseridas. Nesse sentido, nem tudo se presta à brincadeira. Por outro lado, a televisão também promove estruturas lúdicas novas das quais as crianças se apropriam e adaptam.

Nesse sentido, ao incorporar os personagens e os temas das séries de animação e suas representações às estruturas de suas brincadeiras, muitas crianças da pesquisa nos revelam suas maneiras criativas de recontextualizar as histórias, as quais ampliam o universo simbólico das brincadeiras, como nos relatam Mago dos Dragões e Tuzinho:

Mago dos Dragões: Eu brinco de Dragon Ball. Eu faço, por exemplo, uma batalha aleatória, como no Naruto. As batalhas que eu crio, por exemplo, Naruto encontra Madara. Aí, de vez em quando, eu crio sem saber se apareceu no episódio; eu crio só para brincar mesmo na batalha... eu gosto mais de batalha. 
Tuzinho: Eu gosto de ser o herói que se chama Boinax, mas o apelido sobre todos do mundo é Boininha (apelido do Tuzinho)... e tem uma estrela que foi rejeitada pelas outras e foi com muita velocidade para fora do Sistema Solar e aí ela criou um planeta enorme.... E na brincadeira eu vou lá na Terra visitar meus pais, eu sou tipo protetor desse mundo que se chama Coisas, os habitantes são coisas tipo computador que você controla, ele controla outras coisas de tanta inteligência... como eu sou protetor, eu vou lá para o planeta Terra e como eu gosto muito da Turma da Mônica, eu vou lá no bairro Limoeiro para brincar com a turma lá....

Conforme é possível constatar, tais brincadeiras apresentam elementos simbólicos como batalhas, heróis fantásticos, inteligência artificial, fragmentos originários de um repertório midiático que, por meio de montagens e superposições, compõem um novo cenário lúdico, isto é, uma nova narrativa (PILLAR, 2013).

Brincar e assistir televisão são atividades que se integram no cotidiano das crianças, no sentido da sua temporalidade, espacialidade e intertextualidade. Foi possível perceber que são atividades pouco reguladas pelos pais das crianças da pesquisa e compreendidas, em certa medida, como indiferenciadas, uma vez que transitar com fluidez entre uma e outra é muito comum entre elas. Júlia foi a única criança que mencionou a orientação da sua mãe em um outro sentido, apontando a diferença entre assistir televisão e brincar:

Júlia: No final de semana, eu fico mais brincando, porque minha mãe fala que ficar vendo muita televisão isso não é muito bom, que a gente tem que brincar um pouco mais....

Nem todas as crianças brincam diante das telas enquanto assistem aos programas de TV, nem por isso deixam de carregar os referenciais televisivos para as suas brincadeiras, uma vez que fazem isso por meio da recordação, da evocação mental de uma imagem, de uma fala, de um roteiro televisivo ou mesmo das sensações provocadas pela recepção televisiva (GÓMEZ, 2014).

Por meio das brincadeiras, as crianças reproduzem, renegociam e recriam enquanto revivem os referentes televisivos, como também mostrou a pesquisa de Del Rio (2017) ${ }^{5}$. Essas práticas que caracterizam os modos como as crianças da pesquisa interagem com a mídia televisiva é o que, para Gómez (2014), em última instância, definem, demarcam e sustentam a recepção televisiva: o contato multiforme, estendido e variado dos sujeitos com os referentes televisivos.

\section{As séries de animação da TV: as escolhas e as motivações das crianças}

Diferentemente daquilo que é oferecido na chamada TV aberta, um amplo universo de séries de animação é acessado pelas crianças da pesquisa em virtude da oferta dos vários canais de televisão direcionados a elas. A maior parte do grupo pesquisado tem acesso aos canais fechados de TV. Desse grupo, 90\% dizem assistir às séries de animação com mais frequência pelos canais Gloob ${ }^{6}$, Cartoon Network e Nickelodeon, Disney Chanel e Disney XD, canais dirigidos às crianças com mais de seis anos; 10\% dizem assistir mais pelos canais Discovery Kids e Disney Júnior, mais dirigidos aos pré-escolares?

Entre os canais abertos, $23,1 \%$ das crianças dizem assistir às séries de animação pelo $S B T^{8}$. Por outro lado, dizem não assistir à TV Brasil, canal público de televisão, apesar de se tratar de um canal que apresenta muitos programas nacionais de qualidade para o público infantil.

As crianças demonstram bastante autonomia na escolha dos canais infantis de televisão. Algumas poucas dizem seguir indicações de mães e pais, amigos e primos. Outras dizem procurar na TV o que já viram no YouTube, revelando, em certa medida, sua participação na rede transmídia. Ao falarem sobre suas escolhas, todas apresentam uma postura bastante assertiva, demonstrando ter capacidade para lidar de forma autônoma com os conteúdos televisivos dirigidos diretamente a elas:

\footnotetext{
${ }^{5}$ Em pesquisa pioneira sobre o tema, Pablo Del Rio (2017) apontou a existência de forte relação entre a dieta televisiva e a construção do imaginário.

${ }^{6}$ Os canais brasileiros Gloob e Gloobinho são de propriedade da mesma empresa brasileira, a Globosat, do Grupo Globo.

${ }^{7}$ Outros canais por assinatura voltados ao público infantil como Toon Cast, Boomerang e BabyTV não foram citados pelas crianças da pesquisa, assim como os canais NatGeoKids e Gloobinho. Nesse último caso, trata-se de canais que à época estavam menos disponíveis para transmissão por satélite ou a cabo. As crianças também não mencionaram a TV RáTimBum, único canal privado a oferecer, predominantemente, produções nacionais.

8 Sistema Brasileiro de Televisão.
} 
Pesquisadora: Como você escolhe os seus canais?

Mago dos Dragões: Eu escolho os canais assim... depende assim se for legal... eu escolho aleatório, eu escolho por vontade própria, ninguém me diz qual canal que eu tenho que ver, é por vontade própria.

Oliver: Ninguém fala para mim, eu vou mexendo no controle até achar um legal (desenho animado) e aí eu vejo.

Moana: Sou eu que escolho os meus desenhos....

Roberta: Quando eu era pequena, minha mãe colocava para mim (no canal de televisão), mas agora tem uns que eu vejo no YouTube.

Entre as crianças da pesquisa, 57,7\% dizem assistir às séries de animação sozinhas, sem a companhia de outras crianças ou adultos; enquanto 38,5\% dizem assistir com os irmãos mais novos e apenas uma criança, 3,8\%, diz assistir na companhia da mãe. As crianças que assistem sozinhas afirmam gostar dessa experiência e até a preferem porque, segundo elas próprias, passam a ter o controle da TV, enquanto as crianças que assistem com irmãos mais novos precisam negociar com eles o que assistir. Nesse último grupo, $11,5 \%$ das crianças dizem escolher os canais direcionados às crianças pré-escolares em virtude da presença de irmãos mais novos e os demais dizem escolher espontaneamente o que assistem. Trata-se, nesse caso, de uma audiência mais coletiva, formada por crianças de diferentes idades que optam por séries de animação, cujas histórias, personagens, linguagens, poesias e estéticas são mais polissêmicas e por isso têm um largo alcance, isto é, agradam crianças de várias idades.

Portanto, no grupo pesquisado, $96,2 \%$ das crianças assistem às séries de animação sem a presença dos adultos. De acordo com os estudos de Gomes (2012), para muitos adultos, os mundos simbólicos da fantasia e do divertimento são considerados como exclusivos da infância. Nesse caso, as séries de animação estariam diretamente ligadas ao mundo da fantasia e da magia. Por outro lado, o próprio movimento da televisão em direção à segmentação etária e à especialização dos conteúdos audiovisuais dirigidos às crianças também contribui para essa ausência de audiência intergeracional.

Alguns pais, entretanto, mesmo não participando como audiência junto às crianças, procuram acompanhar o que elas estão assistindo na TV, exercendo assim certo tipo de controle ao estabelecer critérios para as escolhas das séries de animação. Tais critérios, no entanto, são, por vezes, questionados pelas próprias crianças que acreditam que as narrativas dos desenhos animados se relacionam a um universo ficcional particular, desconhecido pelos pais, como explicam Tuzinho e Marco Túlio na passagem a seguir:

Tuzinho: Quando eu tinha cinco anos, eu gostava muito de Cartoon Network que tinha desenhos bem legais. Assim, eu gostava de ver escondido da minha mãe, mas eu não podia e também Disney $X D$, né... mas era uma loucura, minha mãe não entendia nada, achava que era diabólico. Aí, cinco anos depois, atualmente, eu posso ver esses desenhos... ela percebeu que é uma loucura. Marco Túlio: Bem loucura, né! Aparece umas coisas assim para entrar um desenho, uma animação, aparece lá um bicho de pé, de uma coisa bem louca, tipo a câmera cai lá no buraco. Ela entendeu que é uma loucura, mas que é legal.... Minha mãe me proíbe de ver Gravity Falls, um Verão de Mistérios, porque é sobre desenho de illuminati.

Tuzinho: É o illuminati...

Marco Túlio: É o Bill.... O Gravity Falls é cheio de Monstros... um cara faz uns três diários... escrevendo sobre ele. Ele tinha seis dedos....

Se por um lado a segmentação da televisão para crianças promove a especialização com a oferta de conteúdos mais apropriados a um determinado público, favorecendo assim o reconhecimento e a autonomia por parte das crianças para lidar com os conteúdos audiovisuais, por outro lado, a televisão cada vez mais segmentada provoca o declínio de uma experiência mais coletiva entre as crianças de idades diversas, uma vez que muitas tendem a buscar canais e programas que as identifiquem de alguma maneira, afastando-se assim daqueles que consideram inadequados. Segundo Fernandes (2003), os processos de comunicação são também fenômenos de produção de identidade, de (re)constituição de sujeitos, de atores sociais. Portanto, os sentidos conferidos a esses processos, dependem muito das identidades que os sujeitos querem construir no interior dos grupos de pertencimento.

É nesse sentido que as crianças da pesquisa buscam se diferenciar com relação às escolhas de canais e programas que assistem, fazendo críticas às séries de animação dirigidas às crianças mais novas. Ao fazerem isso, reivindicam para si o "status" de crianças mais maduras, com gostos mais 
afinados. Em seus relatos sobre os desenhos animados dirigidos aos pré-escolares, muitas crianças da pesquisa tendem a romper com o pacto ficcional, isto é, o estatuto fabuloso proposto pelas narrativas dessas séries (PAULINO et al., 2001) e analisar seus conteúdos fazendo troça de personagens, histórias e linguagens, como demonstra o diálogo abaixo:

Gabriel: Eu não gosto dos desenhos do Discovery Kids.

Lulu: É eles são chatos igual Peppa Pig, pula na lama e aí todo desenho chora... aí pega a bola e o outro vai brincar e aí chora....

Manoel: E o Mickey... eu tenho raiva dele... ele fica falando umas coisas que a gente já sabe.... Larissa: A Dr ${ }^{a}$ Brinquedo é muito criancinha, é muita brincadeira, porque toda hora ela brinca achando que é doutora. Ela faz magia, ressuscita sei lá quem morreu, porque eu sei que isso é mentira. Eu odeio também porque ela fala toda hora.... Espera aí que eu já vou... tem um peixinho lá que foi engolido pela baleia e a doutora foi lá e fingiu que era tubarão.... Que borracha!!!

Para elas, os desenhos animados do universo das crianças pequenas são tolos e ingênuos. Tal julgamento serve a funções sociais que são mais importantes nesse contexto, funções que têm a ver, pelo menos em parte, com a identidade social (BUCKINGHAM, 2007). Nesse sentido, é possível perceber que a divisão do grupo de crianças enquanto audiência televisiva tende a provocar um maior isolamento das crianças em segmentos etários, diminuindo assim a possibilidade de interlocução e interação entre crianças de diferentes idades.

O grupo pesquisado assiste a um universo diversificado de séries de animação, desde as mais tradicionais como Pica Pau e a Casa do Mickey até as mais contemporâneas e populares como Bob Esponja. As crianças da pesquisa citaram 17 tipos diferentes de séries de animação. De todas as séries citadas pelas crianças da pesquisa, as assistidas por um maior número de crianças são: Bob Esponja (27,0\%), Hora de Aventura e O Incrível Mundo de Gumball (23,1\%) e Ben 10 (19,2\%).

Vale mencionar que o universo ficcional das séries de animação assistidas por grande parte das crianças da pesquisa é formado predominantemente por conteúdos audiovisuais de origem estadunidense, sendo as narrativas protagonizadas por personagens masculinos com a idade média de doze anos.

A despeito da multiplicidade e de toda a diversificação que caracterizam os conteúdos audiovisuais produzidos para a audiência infanto-juvenil, segundo Dotro e Salviolo (2016), trata-se ainda de conteúdos, predominantemente, menos específicos culturalmente, com personagens protagonistas brancos e masculinos em maior proporção. Características essas também observadas nas séries de animação que as crianças da pesquisa assistem com maior frequência.

De acordo com Carmona (2016), a reiteração de conteúdos de origem estrangeira, produzidos em contextos culturais únicos e limitados a determinados estereótipos humanos, cria representações da fantasia de um único modo de ser criança e jovem. Para Dotro e Salviolo (2016), a televisão infantil amplia os repertórios culturais de meninos e meninas quando abre uma janela para outros mundos e outras culturas e os coloca em diálogo com a sua própria cultura, quando une o universal e o local, criando espaços para que as crianças possam se reconhecer e reconhecer outras crianças em inúmeras histórias diferentes.

Os conteúdos temáticos com os quais as crianças da pesquisa mais se identificam são as histórias engraçadas, de lutas e poderes com muitas ações, mistério e aventura. Para 61,5\% do grupo pesquisado, o humor, materializado em personagens como Bob Espoja, "zoeiro" e "bugado", nas palavras de Maria Eduarda, uma das crianças da pesquisa, é o que mais as atrai. Para Fuenzalida (2008), as crianças preferem desenhos animados com humor, pois o humor lhes permite relaxar através do riso e reenergizar esforços para que esses sejam novamente empreendidos em tarefas como as escolares.

\section{CONSIDERAÇÕES FINAIS}

A investigação, parcialmente descrita neste artigo, teve como objetivo ouvir as opiniões das crianças e compreender suas ações relativas aos modos como assistem e interagem com as narrativas das séries de animação. Não é um exercício fácil, pois não somente as vozes e as ações infantis estão impregnadas de múltiplos sentidos e são tecidas em vários contextos, como também modificam-se permanentemente em função das interações vivenciadas na cultura. Ademais, encontra-se nesse percurso 
a complexidade que envolve apreender a categoria social da infância e, de forma relacional, compreender as culturas da infância.

Neste artigo, apresentamos os resultados da pesquisa relativos aos modos de interação de um grupo de crianças com as séries de animação da TV. Nesse sentido, um dos aspectos observados na investigação refere-se à presença crescente das telas digitais portáteis e multifuncionais entre as camadas sociais mais populares. Foi possível perceber que, por meio do acesso a tablets, celulares e computadores, as famílias buscam oferecer meios de interatividade e conectividade às crianças. Para isso, constroem alternativas tanto para o consumo quanto para a proteção das crianças, como o uso compartilhado dos equipamentos digitais. Entendem, pois, que a inserção e a participação midiática é algo importante e até fundamental em suas práticas sociais e culturais cotidianas.

Nesse cenário, a televisão ainda mantém a sua importância. É notável o valor que as crianças atribuem à TV, além da sua presença ubíqua em seus cotidianos. Para elas, a televisão é muito mais do que um aparelho multimídia, pois cumpre funções sociais distintas, dependendo dos hábitos familiares.

Nessa relação, o que se observa como mudança são os modos como as crianças interagem com a televisão. Interagir com vários conteúdos midiáticos simultaneamente, por meio de diferentes telas, é o modo mais comum, entre as crianças, de assistir TV. A simultaneidade também está presente, na rotina de algumas crianças, nas formas de brincar, realizar as refeições e as tarefas de casa. No entanto, esse não é o único modo como as crianças vivenciam suas experiências e não são predominantes em suas rotinas. Integradas ao cotidiano, outras experiências regidas por lógicas de tempos mais homogêneos e espaços mais lineares, como as atividades realizadas na escola, também participam do cotidiano das crianças.

A pesquisa demonstrou que as séries de animação configuram-se para as crianças como uma das atividades mais prazerosas que realizam em suas rotinas. Um dos modos de interação com essas narrativas diz respeito à escolha dos canais infantis dirigidos as suas idades. Nesse sentido, percebe-se que os canais segmentados se tornaram para as crianças meios pelos quais elas informam, umas às outras, suas preferências, seus ídolos, suas imagens, seus conteúdos. Foi possível também observar que assistir às séries de animação talvez seja a única atividade, em suas rotinas, que as crianças preferem realizar sozinhas, pois, assim, segundo elas próprias, sentem-se à vontade para navegar por entre canais e programas sem precisar negociar suas decisões com alguém. Além disso, para elas, as narrativas dos desenhos animados se relacionam a um universo ficcional particular, dos seus próprios mundos, e por meio delas a significação e a transposição imaginárias realizam-se sem o compromisso com a racionalidade ou a literalidade. Tal modo de significar essas narrativas audiovisuais permitem às crianças circular no mundo fantástico dando respostas a suas próprias motivações. A partir das relações interativas que estabelecem com esses conteúdos, as crianças criam um repertório de informações, conhecimentos, valores que lhes permitem realizar, com relativa autonomia, escolhas, construir significações e fazer julgamentos.

Por fim, os resultados obtidos, ora apresentados, nos permitem apontar para a grande responsabilidade, nem sempre percebida ou reconhecida, envolvida na produção de conteúdos e produtos midiáticos para as crianças, de um modo geral, e, em particular, das séries de animação voltadas ao público infanto-juvenil.

\section{REFERÊNCIAS}

ABREU, Márcia. Os números da cultura. In: RIBEIRO, Vera Masagão. Letramento no Brasil. São Paulo: Globo, 2004.

ALDERSON, Priscilla. As crianças como pesquisadoras: os efeitos dos direitos de participação sobre a metodologia de pesquisa. Educação \& Sociedade, Campinas, v. 26, n. 91, p. 419-442, maio/ago. 2005.

ARROYO, Miguel G. Indagações que vêm da infância. In: REIS, Magali dos; GOMES, Lisandra Ogg (Orgs.). Infância: sociologia e sociedade. São Paulo: Edições Levana: Attar Editorial, 2015, p. 7-19.

BROUGÈRE, Gilles. Brinquedo e cultura. São Paulo: Cortez, 2010. 
BUCKINGHAM, David. Crescer na era das mídias eletrônicas. São Paulo: Edições, 2007.

BUCKINGHAM, David. Cultura, educação midiática e o lugar da escolarização. Educação \& Realidade, Porto Alegre, v. 35, n. 3, p. 37-58, set./dez. 2010.

CANCLINI, Néstor Garcia. Culturas híbridas. São Paulo: Universidade de São Paulo, 2013.

CARMONA, Beth. Qualidade na produção infantil. Produção audiovisual infantil de qualidade: da inspiração à realização. Curso virtual de TV. 2. ed. São Paulo, SP, 2016.

CORSARO, William A. Sociologia da Infância. 2. ed. Porto Alegre: Artmed, 2011.

DEBORTOLI, José Alfredo Oliveira. Imagens contraditórias das infâncias: crianças e adultos na construção de uma cultura pública e coletiva. In: DEBORTOLI, José Alfredo Oliveira; MARTINS, Maria de Fátima Almeida; MARTINS Sérgio (Orgs.). Infâncias na metrópole. Belo Horizonte: Editora UFMG, 2008, p. 71-86.

DEL RIO, Pablo. Desenvolvimento humano e dieta cultural: dilemas da sociedade contemporânea. In: REGO, Teresa Cristina; BRAGA, Elizabeth. Entrevista: USP, 2017 (no prelo).

DOTRO, Valéria; SALVIOLO, Cielo. Infância, direitos, cultura, cultura audiovisual e novas identidades. Produção audiovisual infantil de qualidade: da inspiração à realização. Curso virtual de TV. 2. ed. São Paulo, SP, 2016.

DUARTE, Rosália (Org.). A televisão pelo olhar das crianças. São Paulo: Cortez, 2008.

FAXINA, Elson; GOMES, Pedro Gilberto. Midiatização: um novo modo de ser e viver em sociedade. São Paulo: Paulinas, 2016.

FERNANDES, Adriana Hoffmann. As mediações na produção de sentidos das crianças sobre os desenhos animados. 2003. 178f. Dissertação (Mestrado em Educação) - Pontifícia Universidade Católica do Rio de Janeiro, Departamento de Educação, Rio de Janeiro.

FERNANDES, Adriana Hoffmann. Infância, cultura e mídia: reflexões sobre o narrar das crianças na contemporaneidade. Currículo Sem Fronteiras, v. 11, n. 1, p. 138-155, jan./jun. 2011.

FUENZALIDA, Valerio. Cambios en la relación de los niños con la televisión. Comunicar - Revista Científica de Comunicación y Educación, Santiago de Chile, v. XV, n. 30, p. 49-54. Grupo Comunicar Huelva, España, 2008.

GENEROZO, Amanda Yara. Produção de sentido na infância: mediações na recepção da série de animação Doug Funnie. 2015. 135f. Dissertação (Mestrado em Comunicação Social) - Universidade Metodista de São Paulo, Faculdade de Comunicação, São Bernardo do Campo.

GOMES, Lisandra Ogg. Particularidades da infância na complexidade social - um estudo sociológico acerca das configurações infantis. 2012. 190f. Tese (Doutorado em Educação) - Universidade de São Paulo, Faculdade de Educação, São Paulo.

GOMES, Lisandra Ogg; AVANZINI, C.M.V. Concepção de criança, infância e educação. In: BRASIL. Ministério da Educação. Secretaria de Educação Básica. Diretoria de Apoio à Gestão Educacional. A criança no ciclo da alfabetização. Pacto Nacional pela Alfabetização na Idade Certa. Caderno 02. Brasília: MEC, SEB, 2015.

GÓMEZ, Guillermo Orozco. Recepção midiática, aprendizagens e cidadania. São Paulo: Paulinas, 2014. 
LOPES, Maria Immacolata Vassallo de. Algumas reflexões metodológicas sobre a recepção televisiva transmídia. Revista GEMInIS - Edição Especial - JIG, São Carlos, São Paulo, p. 13-16, maio, 2014.

MASCI, Carolina. Convergência - novas telas, cultura digital e infâncias. Produção audiovisual infantil de qualidade: da inspiração à realização. Curso virtual de TV. 2. ed. São Paulo, SP, 2016.

NESTERIUK, Sérgio. Dramaturgia de série de animação. I Programa de Fomento à Produção e Teledifusão de séries de animação brasileiras - ANIMA TV. São Paulo, 2011.

PACHECO, Elza Dias. Televisão, criança e imaginário: contribuições para a integração EscolaUniversidade-Sociedade. Rio de Janeiro: PUC, 1999.

PAULINO, Graça et al. Tipos de textos, modos de leitura. Belo Horizonte: Formato, 2001.

PILLAR, Analice Dutra. Inscrições do contemporâneo em narrativas audiovisuais: simultaneidade e ambivalência. Educação, Porto Alegre, v. 36, n. 3, p. 306-313, set./dez. 2013.

QVORTRUP, Jens. Nove teses sobre "infância como um fenômeno social". Pro-Posições, Campinas, v. 22, n. 1 (64), p. 199-211, jan./abr. 2011

SALGADO. Raquel Gonçalves. Ser criança e herói no jogo e na vida: a infância contemporânea, o brincar e os desenhos animados. 2005. 245f. Tese (Doutorado em Psicologia) - Pontifícia Universidade Católica do Rio de Janeiro, Departamento de Psicologia, Rio de Janeiro.

SARMENTO, Manuel Jacinto. Imaginário e culturas da infância. Braga: Universidade do Minho, 2003.

SARMENTO, Manuel Jacinto. As culturas da infância nas encruzilhadas da segunda modernidade. In: SARMENTO, M. J.; CERIZARA, A. B. Crianças e miúdos: perspectivas sócio pedagógicas da infância e da educação. Porto: ASA, 2004.

SARMENTO. Manuel Jacinto. Gerações e alteridade: interrogações a partir da sociologia da infância. Educação \& Sociedade, Campinas, v. 26, n. 91, p. 361-378, maio/ago. 2005.

SARMENTO, Manuel Jacinto. Sociologia da Infância: correntes e confluências. In: SARMENTO, Manuel Jacinto; GOUVÊA, Maria Cristina Soares de (Orgs.). Estudos da Infância: educação e práticas sociais. Petrópolis: Vozes, 2008.

SOARES, Natália Fernandes. A investigação participativa no grupo social da infância. Currículo Sem Fronteiras, v. 6, n.1, p. 25-40, jan./jun. 2006.

Submetido: $15 / 06 / 2020$

Aprovado: 30/10/2020 